\title{
p53-inducible long non-coding RNA PICART1 mediates cancer cell proliferation and migration
}

\author{
YU CAO ${ }^{1}$, MINGLIN LIN ${ }^{1}$, YIWEN BU ${ }^{1}$, HONGYAN LING ${ }^{1}$, YINGCHUN HE ${ }^{1,2}$, \\ CHENFEI HUANG ${ }^{1}$, YI SHEN ${ }^{1}$, BOB SONG $^{3}$ and DELIANG CAO ${ }^{1,2}$
}

\begin{abstract}
${ }^{1}$ Department of Medical Microbiology, Immunology and Cell Biology, Simmons Cancer Institute, Southern Illinois University School of Medicine, Springfield, IL 62794, USA; ${ }^{2}$ Hunan Cancer Hospital and The Affiliated Cancer Hospital of Xiangya School of Medicine, Central South University, Changsha,

Hunan 410013, P.R. China; ${ }^{3}$ University of Missouri-Kansas City, Kansas City, MO 64108, USA
\end{abstract}

Received September 10, 2016; Accepted February 14, 2017

DOI: $10.3892 /$ ijo.2017.3918

\begin{abstract}
Long non-coding RNAs (IncRNAs) function in the development and progression of cancer, but only a small portion of lncRNAs have been characterized to date. A novel lncRNA transcript, $2.53 \mathrm{~kb}$ in length, was identified by transcriptome sequencing analysis, and was named p53-inducible cancer-associated RNA transcript 1 (PICART1). PICART1 was found to be upregulated by $\mathrm{p} 53$ through a p53-binding site at -1808 to $-1783 \mathrm{bp}$. In breast and colorectal cancer cells and tissues, PICART1 expression was found to be decreased. Ectopic expression of PICART1 suppressed the growth, proliferation, migration, and invasion of MCF7, MDA-MB-231 and HCT116 cells whereas silencing of PICART1 stimulated cell growth and migration. In these cells, the expression of PICART1 suppressed levels of p-AKT (Thr308 and Ser473) and p-GSK3 $\beta$ (Ser9), and accordingly, $\beta$-catenin, cyclin D1 and c-Myc expression were decreased, while $\mathrm{p} 21^{\text {Waf/cipl }}$ expression was increased. Together these data suggest that PICART1 is a novel p53-inducible tumor-suppressor lncRNA, functioning through the AKT/GSK3 $\beta / \beta$-catenin signaling cascade.
\end{abstract}

Correspondence to: Dr Deliang Cao, Department of Medical Microbiology, Immunology and Cell Biology, Simmons Cancer Institute, Southern Illinois University School of Medicine, 913 N. Rutledge Street, Springfield, IL 62794, USA

E-mail: dcao@siumed.edu

Abbreviations: PICART1, p53-inducible cancer-associated RNA transcript 1; ANRIL, antisense non-coding RNA in the INK4 locus; HOTTIP, HOXA distal transcript antisense RNA; HOTAIR, HOX transcript antisense RNA; BCAR4, breast cancer anti-estrogen resistance 4; lincRNA-p21, tumor protein p53 pathway corepressor 1; XIST, inactive X specific transcripts; STAT3, signal transducer and activator of transcription 3; HDM2, human double minute 2 homolog; RITA, reactivation of $\mathrm{p} 53$ and induction of tumor cell apoptosis; pAKT, phosphate protein kinase B (PKB); pGSK3 $\beta$, phosphate glycogen synthase kinase $3 \beta$

Key words: long non-coding RNA, PICART1, p53, AKT, $\beta$-catenin, GSK3 $\beta$, tumor suppressor

\section{Introduction}

Based on the transcript size, non-coding RNAs (ncRNAs) are divided into two groups: small non-coding RNAs and long non-coding RNAs (lncRNAs) $(1,2)$. Biologically, lncRNAs are specifically characterized as RNA transcripts that are longer than $200 \mathrm{nt}$ in length and do not have an open reading frame (ORF). To date, several biological functions of lncRNAs have been described, including i) signal molecules in gene transcription, ii) decoys to titrate transcription factors, iii) directors for chromatin, and iv) scaffolds for proteins to form ribonucleoprotein complexes $(1,2)$. Differential expression of IncRNAs is a well-known event and regarded as a hallmark of cancer (3). Many lncRNAs have been characterized in cancers and they function as tumor suppressors or oncogenes. For example, imprinted H19 is an lncRNA first reported in mammalian cells, encoded by a gene located on chromosome 11p15.5; H19 is involved in fetal and placental growth (4). H19 has been reported as a marker in breast and cervical cancers (5). In gastric cancer, the lncRNA H19 promotes carcinogenesis and metastasis by interacting with miR-675 (4). Other characterized lncRNA oncogenes and tumor suppressors include ANRIL, HOTTIP, HOTAIR, BCAR4, 1ncRNA-p21 and XIST (6).

In cancer, lncRNAs have emerged as critical players involved in signaling transduction, DNA damage repair, cell cycle control, epigenetic modifications, and chromosome modeling (6). For example, the lncRNA HOTAIR regulates chromatin dynamics and promotes metastasis in multiple types of cancers, including breast cancer, colorectal cancer, non-small cell lung carcinoma and hepatocellular carcinoma (7). The aberrant activation of cellular signal transduction is well documented in cancer, promoting unlimited growth and proliferation of cancer cells. IncRNAs function in cellular signaling pathways and modulate cancer development and progression. For instance, the lncRNA ATB stabilizes IL-11 mRNA and activates the STAT3 signaling cascade which drives cell colonization at distant metastatic sites (8). BCAR4 (breast cancer anti-estrogen resistance 4) increases migration and invasion of breast cancer cells through activation of a non-canonical Hedgehog signaling 
pathway (9). CCAT2 (colon cancer-associated transcript 2) and MALAT1 (metastasis-associated lung adenocarcinoma transcript 1) promote cancer progression and metastasis through activation of the Wnt signaling pathway $(10,11)$. The present study characterized a new tumor suppressor lncRNA, named p53-inducible cancer-associated RNA transcript 1 (PICART1). This PICART1 lncRNA consists of 3 exons, 2533 bp in length (gene ID: 284080) and is encoded by a gene located at $17 \mathrm{q} 21.33$. Our data demonstrated that PICART1 inhibited cell proliferation and migration in breast and colorectal cancer cells through suppression of the AKT/ GSK3 $\beta / \beta$-catenin signaling pathway, functioning as a tumor suppressor.

\section{Materials and methods}

Ethics statement. IRB protocol was approved by Springfield Committee for Research Involving Human Subjects.

Human sample procurement. Frozen breast ( $\mathrm{n}=50$ pairs) and colon ( $\mathrm{n}=50$ pairs) cancer and matched normal adjacent tissues were procured following approved IRB protocol from the Tissue Bank of Simmons Cancer Institute at the Southern Illinois University. These frozen specimens were used for RNA extract and real-time RT-PCR analyses of PICART1 expression.

Cell culture. Human breast cancer cells (MCF7 and MDA-MB-231) were cultured in Dulbecco's modified Eagle's medium (DMEM; Thermo Fisher Scientific, Waltham, MA, USA) supplemented with $10 \%$ FBS (Sigma-Aldrich, St. Louis, MO, USA), $1 \%$ penicillin/streptomycin at $37^{\circ} \mathrm{C}, 5 \% \mathrm{CO}_{2}$. The basal medium for HEK 293T cells was the same as that for MCF7 cells, but additional $2.0 \mathrm{mM}$ L-glutamine was added. Human colorectal cancer cells (HCT116 and HCT8) were grown in RPMI-1640 medium (Thermo Fisher Scientific) supplemented with $10 \%$ FBS (Sigma-Aldrich), $1 \%$ penicillin/streptomycin at $37^{\circ} \mathrm{C}$, and $5 \% \mathrm{CO}_{2}$. Human mammary epithelial cells (MCF10A) were cultured with a commercial MEGM kit (catalog no. CC-3150) supplemented with $100 \mathrm{ng} /$ $\mathrm{ml}$ cholera toxin. All cells were purchased from the American Type Culture Collection (ATCC) (Manassas, VA, USA).

RNA preparation and quantitative RT-PCR. Total RNA was extracted using TRIzol reagent (Invitrogen, CA, USA). RNA was treated with RNase-free DNase I and the first strand cDNA was synthesized from $1.0 \mu \mathrm{g}$ of total RNA with oligo dT primers and Moloney Murine Leukemia Virus (M-MLV) reverse transcriptase according to the manufacturer's protocol (New England Biolab, Beverly, MA, USA). To detect the PICART1 transcript, the SYBR Green method was used with PICART1 primers: forward 5'-AGGCAGCTACTGTAA TAAT-3' and reverse 5'-GTACCCTGGGCCTTTCTTAC-3'. The internal control was $\beta$-actin. $\Delta \Delta C$ t values were used to determine relative expression levels as fold changes (12).

Plasmid construction. For ectopic expression of PICART1, its cDNA was amplified by RT-PCR and then subcloned into the pCDH-CMV-EF1-copGFP vector (System Biosciences, Mountain View, CA, USA) (13). Conventional sequencing was conducted to confirm the cDNA sequence. PCR primers were as follows: F1 forward,5'-GCTGCTGCTGCTGAAAAGGC-3', and reverse, 5'-CTGGCAGATTCTGAGCCAGG-3'; F2 forward, 5'-CCTGGCTCAGAATCTGCCAG-3' and reverse, 5'-GAATTCATGCATAAGGGCCCATGTGC-3'; F3 forward, 5'-ATGCATTCACAGGTGTTTGCCTATGC-3' and reverse, 5'-ATGCATCCCACTTTGGTATTTTAGTC-3'; shRNA-2 forward, 5'-AGGCAGCTACTGTAATAAT-3' and reverse, 5'-ATTATTACAGTAGCTGCCT-3'; shRNA-3 forward, 5'-TCCTGTGGAGAAGCCTCTTTACT-3' and reverse, 5'-AGTAAAGAGGCTTCTCCACAGGA-3'. High Fidelity Phusion DNA polymerase (Thermo Fisher Scientific) was used for PCR amplification. PICART1 promoter was amplified by PCR using human genomic DNA as templates and subcloned into the pGL4 luciferase vector (Promega, Madison, WI, USA). PCR primers were as follows: -3000-bp forward, 5'-CGAGCCCAGCTGGCTCTCCCAAATG-3', -1592-bp forward, 5'-ATCTGTGGAATGCAGGGAAGATGTC-3', -1227-bp forward, 5'-AACAGGCTAGTGCTGGGTACTCG-3' and -681 bp forward, 5'-TAAGATCCGTGGGTCTATCTTCC TG-3'. The common reverse primer was 5'-CCAGATGCG CCAATGCCAGGTCTCT-3'. Primers for point mutations were mut 1 forward, 5'-CCTCTTCCTCCTGGAACGTCTC CTG-3' and reverse, 5'-CAGGAGACGTTCCAGGAGGAAG AGG-3'; mut2 forward, 5'-CCTCTTTTTCCTGGATTTTCT CCTG-3 and reverse 5'-GGAGGAAAAATCCCAAAAA AGGCTG-3'.

ChIP (chromatin immunoprecipitation) assay. MCF7 cells were fixed in $1 \%$ formaldehyde for $10 \mathrm{~min}$ and cell lysates were prepared for immunoprecipitation following protocol according to a previous published study (14). Immune complexes were collected with $50 \mu \mathrm{l}$ of protein G-agarose beads and DNA was extracted using proteinase $\mathrm{K}$ digestion and phenol/ chloroform extraction. PCR amplification was performed with forward, 5'-CTGAGGCCACGGCAGAGAGA-3' and reverse, 5'-GGCATGAGGGCGTCTGGTGG-3' primers at -1763 and -1728 bp of the PICART1 promoter.

Cell transfection and infection. For packaging of lentiviruses, 293T cells were seeded in $10-\mathrm{cm}$ dishes. Cells were transfected with expression plasmids pCDH, PICART1, pGreenpuro, shRNA-2 or shRNA-3 with packaging plasmids REV, VSVG and GAG for $24 \mathrm{~h}$. Then the medium was changed and cells were continued to culture for $48 \mathrm{~h}$ to collect viral particles (15). For infection, cells were spread at $60 \%$ of confluence and exposed to lentiviruses (MOI=1) with 1:2000 diluted Polybrene (Millipore, Billerica, MA, USA).

Western blotting. Cells were lysed in cell lysis buffer (Roche, Indianapolis, IN, USA) with a protease inhibitor cocktail followed by centrifugation at $14,000 \mathrm{rpm}$ for $5 \mathrm{~min}$ to collect supernatant proteins. Protein separation, membrane blotting and antibody probing were conducted as previously described (16). Antibodies used were anti-p53 (dilution 1:1000; Santa Cruz Biotechnology, Santa Cruz, CA, USA), antipAKT (Thr308) (dilution 1:1000; Cell Signaling Technology, Danvers, MA, USA), anti-pAKT (Ser473) (dilution 1:1000; Cell Signaling Technology), anti-AKT (dilution 1:1000; Cell Signaling Technology), anti-GSK3 $\beta$ (S9) (dilution 1:1000, Cell Signaling Technology), anti-GSK3 $\beta$ (dilution 1:1000; 
Table I. Top 10 selected LncRNAs in RNA sequencing.

\begin{tabular}{lllllc}
\hline lncRNA & Regulation & $\begin{array}{c}\text { Fold } \\
\text { change }\end{array}$ & \multicolumn{1}{c}{ Official full name } & Location & $\begin{array}{c}\text { Exon } \\
\text { numbers }\end{array}$ \\
\hline LOC33161 & Down & -2.65 & $\begin{array}{l}\text { Long intergenic non-protein } \\
\text { coding RNA 1001 }\end{array}$ & Chr11p15.5 & 100133161 \\
LOC32287 & Down & -1.88 & LOC100132287 & Chr1p36.33 & 100132287 \\
LOC94362 & Down & -2.86 & LOC100294362 & 100294362 \\
LOC72216 & Down & -2.60 & LOC100272216 & Chr17 & 100272216 \\
LOC30091 & Down & -2.36 & Long intergenic non-protein & Chr3q25.31 & 730091 \\
LOC28978 & Up & 10.05 & UNC5B antisense RNA 1 & Chr10q22.1 & 728978 \\
LOC30102 & Up & 1.79 & $\begin{array}{l}\text { Quinone oxidoreductase-like } \\
\text { protein 2 pseudogene }\end{array}$ & Chr1q25.2 & 730102 \\
LOC00494 & Up & 1.10 & Long intergenic non-protein & Chr20q13.13 & 284749 \\
LOC88692 & Up & 1.90 & LOC388692 & & 1 \\
PICART1 & Up & $\mathbf{4 . 5 6}$ & LOC284080 & Chr1q21.2 & 38692 \\
\hline
\end{tabular}

PICART1, p53 inducible cancer-associated RNA transcript 1.

Cell Signaling Technology), anti- $\beta$-catenin (dilution 1:1000; Cell Signaling Technology), anti-cyclin D1 (dilution 1:1000; Cell Signaling Technology), anti-c-Myc (dilution 1:500; Santa Cruz Biotechnology) and anti-p21 ${ }^{\text {Waf/cip1 }}$ (dilution 1:1000; Cell Signaling Technology). $\beta$-actin was used as an internal control.

Luciferase activity. The dual luciferase assay kit (Promega, Madison, WI, USA) was used following the manufacturer's protocol. Cells were collected and lysed for luciferase assay $48 \mathrm{~h}$ after transfection. Renilla luciferase was used as an internal control for normalization (17).

Transwell migration and invasion assays. Transwell migration assays were performed using $8.0-\mu \mathrm{m}$ pore inserts (BD Biosciences, San Jose, CA, USA). A total of $2-5 \times 10^{4}$ cells were suspended in $500 \mu \mathrm{l}$ serum-free medium and loaded into upper wells; lower chambers were filled with $750 \mu \mathrm{l}$ complete medium with $10 \%$ FBS. For the invasion assays, inserts were coated with $1 \mathrm{mg} / \mathrm{ml}$ Mitrigel and pre-incubated at $37^{\circ} \mathrm{C}$ for $2 \mathrm{~h}$. A total of $3-7 \times 10^{4}$ cells were suspended in $500 \mu \mathrm{l}$ serum-free medium and loaded into the coated inserts; lower chambers were filled with $750 \mu \mathrm{l}$ complete medium. Migration and invasion chambers were incubated in a $5 \% \mathrm{CO}_{2}$ incubator at $37^{\circ} \mathrm{C}$ for $36-48 \mathrm{~h}$. Cells were stained and counted under a microscope for 5 random fields (18).

Wound healing assays. Cells were seeded in 6-well plates at $90 \%$ confluence and cultured in medium supplemented with $2 \%$ FBS. Scratches were made using a 200- $\mu 1$ tip. Migration distance was estimated from images (4 fields) taken at each time point (18).

Cell proliferation. For the cell proliferation assays, cells were split into 96-well plates at 2000-3000 cells/per well. Viable cells were measured by tetrazolium salt, 3-(4,5-dimethylthiazol2-yl)-2,5-diphenyltetrazolium bromide (MTT) assays over 5 days (19). For cell counting assays, cells were split into 12-plates. At the indicated time points, cells were collected and subjected to trypan blue staining. Viable cells were counted in a Vi-cell counter (Beckman Coulter, Brea, CA, USA).

Statistical analysis. Data were analyzed by SPSS Statistical software (SPSS Inc., Chicago, IL, USA). Values are shown as mean \pm SD. The Student's t-test was used for the analyses. A P-value of $\leq 0.05$ was considered to indicate a statistically significant difference.

\section{Results}

Identification of a novel long non-coding RNA transcript PICART1. p53 is a master transcription factor regulating the expression of a wide range of coding and non-coding genes. HDM2 (MDM2 in mice) binds to the p53 protein and inhibits its transactivation activity in target gene expression and triggers ubiquitination-proteasome degradation (20). A lead compound, RITA (reactivation of p53 and induction of tumor cell apoptosis), binds to p53 and thus leads to p53 conformational changes and dissociation from HDM2, reactivating p53 (21). Using transcriptome RNA sequencing analysis in MCF7 cells (p53wt) treated with RITA (100 nM), we recognized 10 new non-coding RNA species with pivotal expression changes in response to RITA treatment. Table I summarizes the basic information of these new RNA transcripts induced by RITA. A non-coding RNA transcript LOC84080 was upregulated by RITA/p53 >4.5 fold. This RNA species was $2533 \mathrm{bp}$ in length, and identified as being a long non-coding RNA (lncRNA). We named it p53 inducible cancer-associated RNA transcript 1 (PICART1). 
A

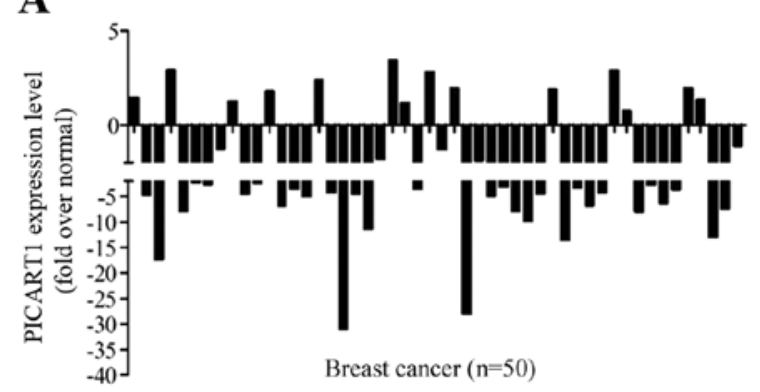

C

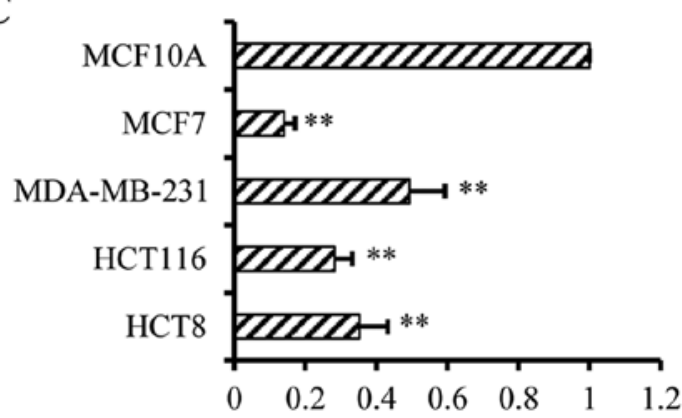

B

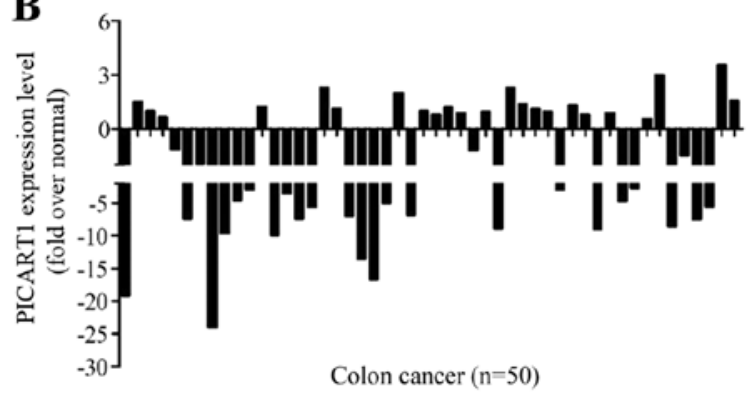

Figure 1. Identification of PICART1 and its expression in breast and colon cancer tissues and cells. Total RNA was extracted using a TRIzol reagent for transcriptome sequencing analysis or quantitative real-time RT-PCR with GAPDH mRNA as an internal control. (A) PICART1 expression in breast cancer tissues ( $n=50$ pairs). Data are expressed as fold over the PICART1 expression level in the matched adjacent normal tissue. (B) PICART1 expression in colon cancer tissues ( $\mathrm{n}=50$ pairs). Data are expressed as fold over the PICART1 expression level in the matched adjacent normal tissue. (C) PICART1 expression in breast and colon cancer cell lines. Results are expressed as fold over the PICART1 RNA levels in the MCF10A cell line. Data indicate mean \pm SD from three independent experiments. ${ }^{* *} \mathrm{P}<0.01$ compared to MCF10A.
PICART1 is downregulated in breast and colon cancer cell lines and tissues. As a potential p53 target, PICART1 was first examined in cancer cell lines and tissues to see whether this lncRNA species is involved in tumor development and progression. As shown in Fig. 1A, in 50 paired breast cancer and adjacent normal tissues, PICART1 expression was decreased by $>2$-fold in $32(64.0 \%)$ breast cancer cases compared to that in the adjacent normal breast tissues, with a maximal decrease of $>30$-fold. Similarly, in 50 paired colon cancer and adjacent normal tissues, PICART1 expression was decreased by $>2$-fold in $23(46 \%)$ malignant tissues with a maximal decrease of $>25$-fold (Fig. 1B). PICART1 expression was also downregulated in cancer cell lines. As shown in Fig. 1C, PICART1 expression was high in non-transformed human mammary epithelial cells MCF10A, but decreased by 7.0-, 2.0-, 3.0- and 2.5-fold in the MCF7, MDA-MB-231, HCT116 and HCT8 cells, respectively, compared to the MCF10A cells. These data suggest that PICART1 is downregulated in breast and colon cancer cell lines and tissues, functioning as a potential tumor suppressor.

PICART1 is upregulated by p53. As downregulation of PICART1 was noted in breast and colon cancers, we aimed to elucidate the regulatory mechanism of PICART1 expression. We first verified its induction by RITA using real-time RT-PCR. As shown in Fig. 2A, RITA at $100 \mathrm{nM}$ induced PICART1 expression early at $12 \mathrm{~h}$, and the induction reached a peak of nearby 15-fold in HCT116 cells and 30-fold in MCF7 cells at $24 \mathrm{~h}$. Similarly, RITA also induced PICART1 expression in MCF7 and HCT116 cells in a dose-dependent manner (Fig. 2B). At $1.0 \mu \mathrm{M}$ of RITA, PICART1 was upregulated over 20 - and 30 -fold in the HCT116 and MCF7 cells, respectively. These data confirmed the induction of PICART1 by RITA. RITA is a p53 activator (21), and thus we aimed to ascertain whether RITA induces PICART1 expression through a p53-mediated mechanism. To test this hypothesis, we determined the effects of doxorubicin on PICART1 expression. Doxorubicin induces DNA damage and thus activates p53, which is a different mechanism from that of RITA. Our results showed that doxorubicin triggered expression of PICART1 in MCF7 cells in a time- and dose-dependent manner (Fig. 2C). Furthermore, we confirmed the regulation of p53 on PICART1 expression by targeted gene expression or silencing. As shown in Fig. 2D, PICART1 expression in MCF7 cells was increased 3-fold by p53 ectopic expression whereas p53 silencing decreased PICART1 expression to $10 \%$ compared to the vector control cells. Similar results were observed in HCT116 cells (Fig. 2D, right). These data suggest that p53 induces PICART1 expression.

p53 upregulates PICART1 expression through a p53 response element in its promoter. As a transcription factor, p53 may stimulate PICART1 expression through a promoter-mediated mechanism. With a p53 scan program MatInspector software (https://www.genomatix.de/online), we analyzed the promoter region of PICART1 and identified 3 putative p53 response elements $\sim 3000$ bp upstream of PICART1 transcripts (Fig. 3A). Specifically, these 3 putative p53 response elements were located at -1808 to $-1783 \mathrm{bp},-1524$ to $-1499 \mathrm{bp}$, and -1131 to $-1106 \mathrm{bp}$. We then cloned this 3000 -bp promoter fragment into a pGL4 basic luciferase reporter vector and constructed four promoter-luciferase reporter plasmids that contained $-3000,-1592,-1227$ and $-681 \mathrm{bp}$, respectively. The $-3000 \mathrm{bp}$ hosted all three putative p53 response elements, the $-1592 \mathrm{bp}$ contained putative p53 response elements 2 and 3 , and the -1227 bp had only putative p53 regulatory element 3 (Fig. 3B). These promoter fragments all demonstrated promoter activity driving luciferase reporter expression, but the promoter activity of -1227 and -681 bp vectors was lower compared to the longer -1592 and $-3000 \mathrm{bp}$ fragments, indicating existence of enhancer(s) in the longer region (Fig. 3B). 
A

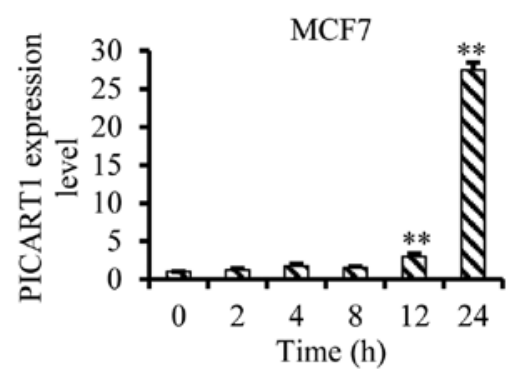

B

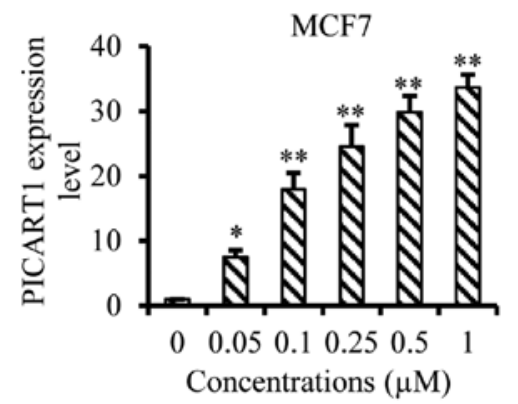

C

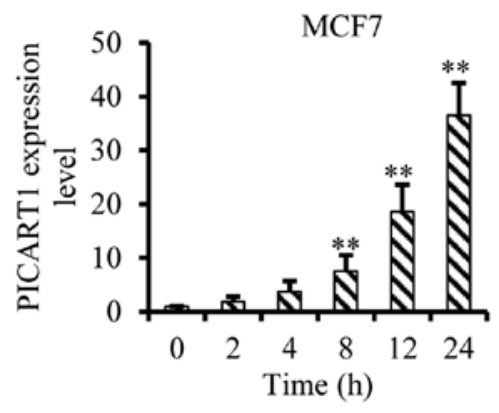

D
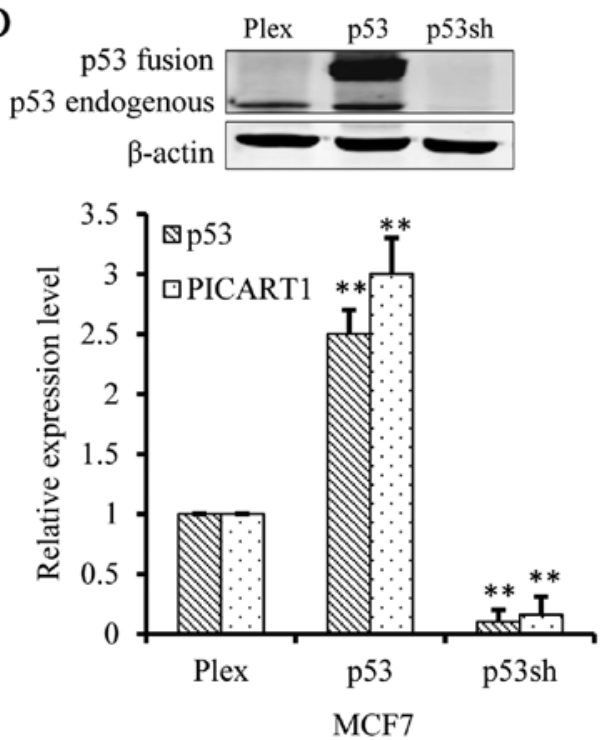
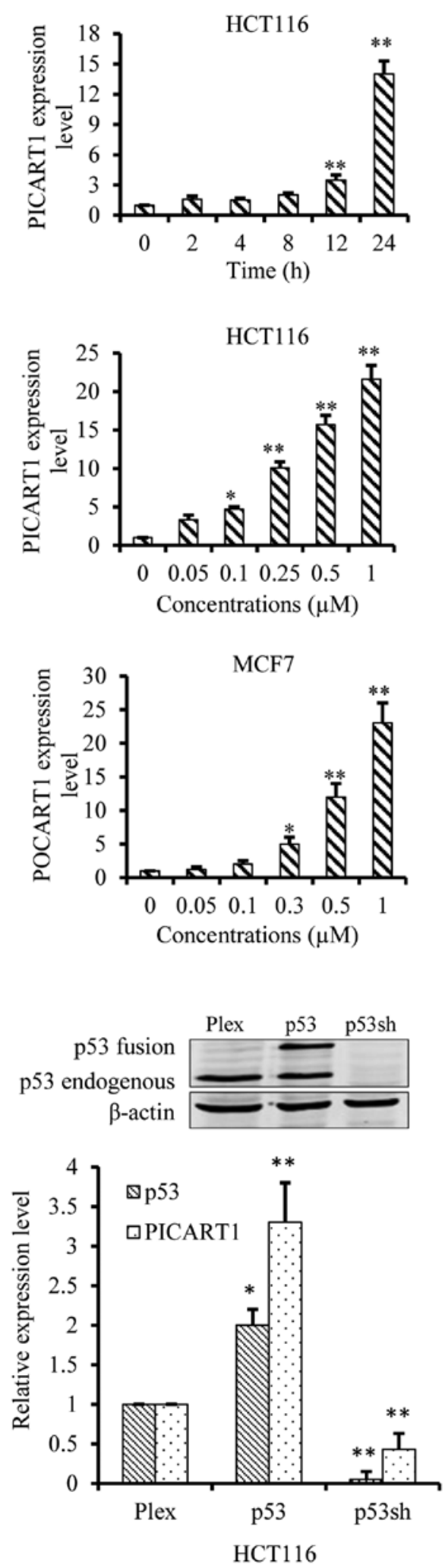

Figure 2. Induction of PICART1 expression by RITA and p53. PICART1 RNA levels were estimated by quantitative real-time RT-PCR. (A) Time-dependent induction by RITA. MCF7 cells were treated with $100 \mathrm{nM}$ RITA and HCT116 cells were exposed to $500 \mathrm{nM}$ RITA for the indicated time points. (B) Dosedependent induction by RITA. MCF7 and HCT116 cells were treated with RITA at indicated concentrations for $24 \mathrm{~h}$. (C) Time- and dose-dependent induction by doxorubicin. MCF7 cells were treated by doxorubicin at different concentrations for $24 \mathrm{~h}$ or at $1.0 \mu \mathrm{M}$ of doxorubicin for different time points. (D) Induction by p53. MCF7 and HCT116 cells were introduced with a p53-EGFP fusion protein or p53 shRNA. Top panels: expression of fusion p53 and endogenous p53. Bottom panels: p53 mRNA (left) and PICART1 RNA (right) levels. Data indicate mean \pm SD from three independent experiments. ${ }^{*}<0.05$ and ${ }^{* *} \mathrm{P}<0.01$ compared to controls.

We further tested the response of these promoter fragments to RITA. Our results showed that the -3000-bp fragment was activated by RITA at 0.05 to $0.5 \mu \mathrm{M}$ in a dose-dependent manner in both MCF7 and HCT116 cells (Fig. 3C), but the 
A

\begin{tabular}{|l|c|c|c|}
\hline & \multicolumn{2}{|c|}{ p 53 REs } & Sequence \\
\hline 1 & -1808 & -1783 & cctctgaagcctggaCATGctcctg \\
\hline 2 & -1524 & -1499 & cagccagagttgggaCAAGtcctcc \\
\hline 3 & -1131 & -1103 & ggggtggcgtccagaCAGGttctgg \\
\hline
\end{tabular}

p53 REs: p53 regulatory elements

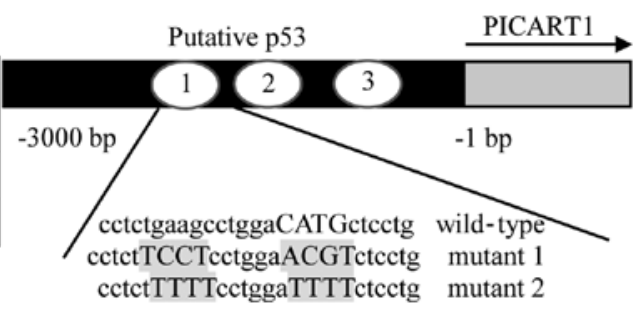

cctctTTTTcetggaTTTTctcetg mutant 2

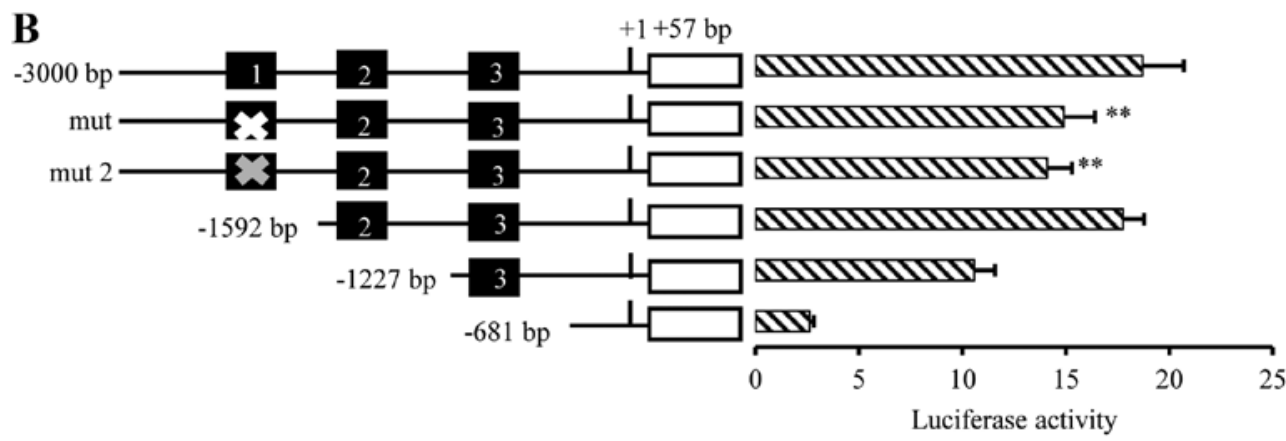

C
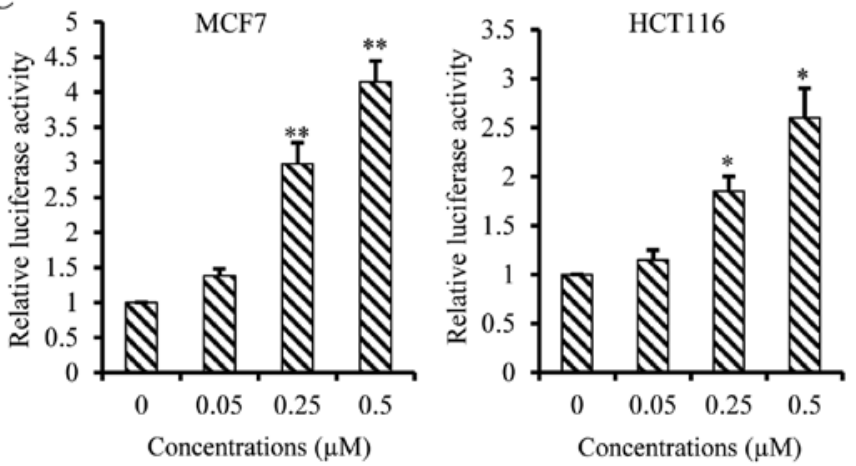

D


F
E



Figure 3. Regulation of PICART1 promoter activity by p53. (A) Putative p53 binding sites in PICART1 promoter. Left: location of three putative binding elements. Right: two mutants of p53 binding site 1. (B) Basal activity in MCF7 cells of PICART1 promoter with different lengths or harboring mutations at p53 binding site 1. (C) Induction of promoter activity by RITA. MCF7 and HCT116 cells were transfected with PICART1 promoter for $24 \mathrm{~h}$, followed by RITA treatment at indicated concentrations for $24 \mathrm{~h}$ and then luciferase reporter activity assays. (D) p53 regulation of promoter activity. MCF7 and HCT116 cells were co-transfected with PICART1 promoter-luciferase vector and plex (vector control), p53 or p53shRNA. Luciferase activity was measured at $48 \mathrm{~h}$ after transfection. (E) ChIP assay, showing binding of p53 to the PICART1 promoter in MCF7 cell. (F) Abrogation of p53 regulation in mutants of p53 binding element 1. MCF7 cells were co-transfected with mutant PICART1 promoter and plex, p53 or p53shRNA. Luciferase activity was measured at $48 \mathrm{~h}$ after transfection. Data indicate mean \pm SD from three independent experiments. ${ }^{*} \mathrm{P}<0.05$ and ${ }^{* * *} \mathrm{P}<0.01$ compared to vector control.

-1592 bp fragment was not (data not shown). These data suggested that the putative p53 element 1 is functional, but the putative p53 elements 2 and 3 are not. We then conducted co-transfections of the PICART1 promoter $(-3000 \mathrm{bp})$ with p53 gene or shRNA in MCF7 and HCT116 cells. Our results demonstrated that luciferase activity was increased by $\mathrm{p} 53$ expression but decreased by $\mathrm{p} 53$ silencing compared to the vector control (Fig. 3D). We examined binding of p53 to this putative element 1 in the PICART1 promoter using a ChIP assay. The results demonstrated that $\mathrm{p} 53$ binds to the element 1 (Fig. 3E). We further characterized this putative p53 element 1 by targeted point mutations (Fig. 3A, right). As a result, mutations at the putative $\mathrm{p} 53$ responsive element 1 lowered down basal activity of the PICART1 promoter (Fig. 3B) and 
A

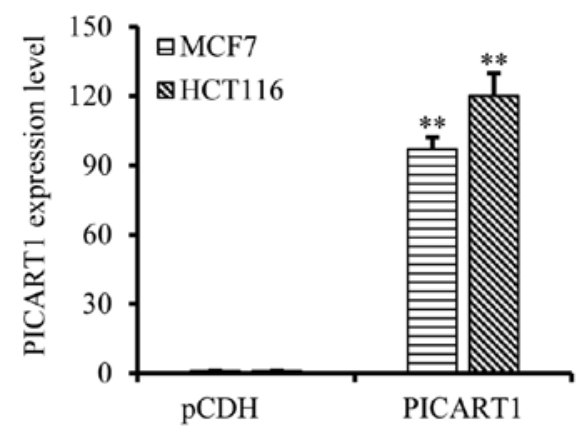

B

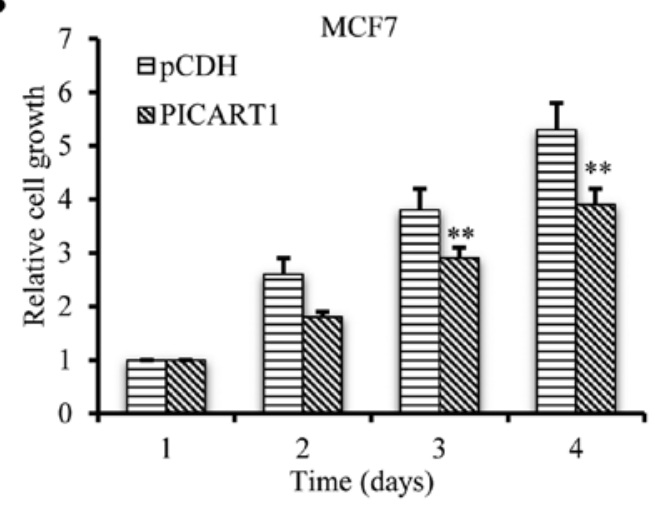

C

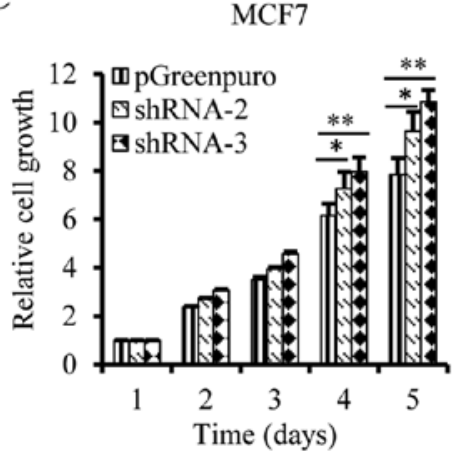

D

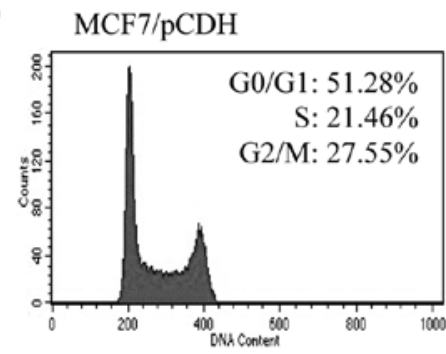

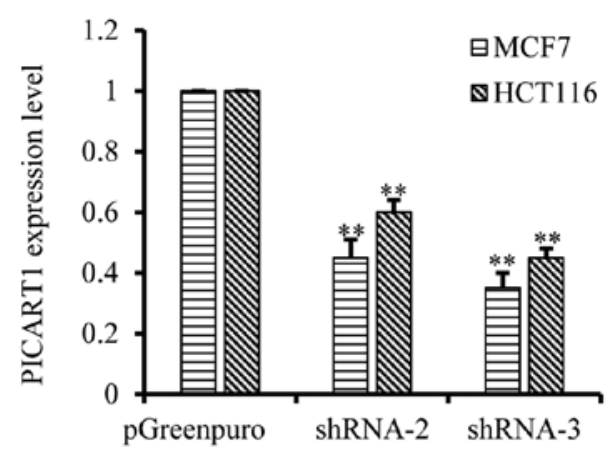

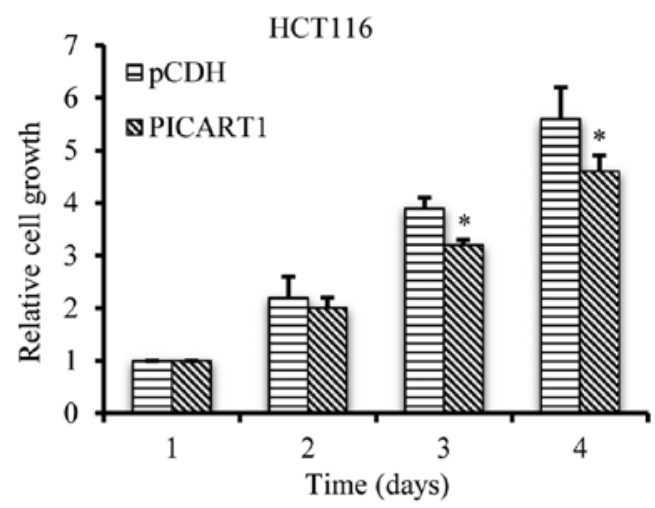

HCT116
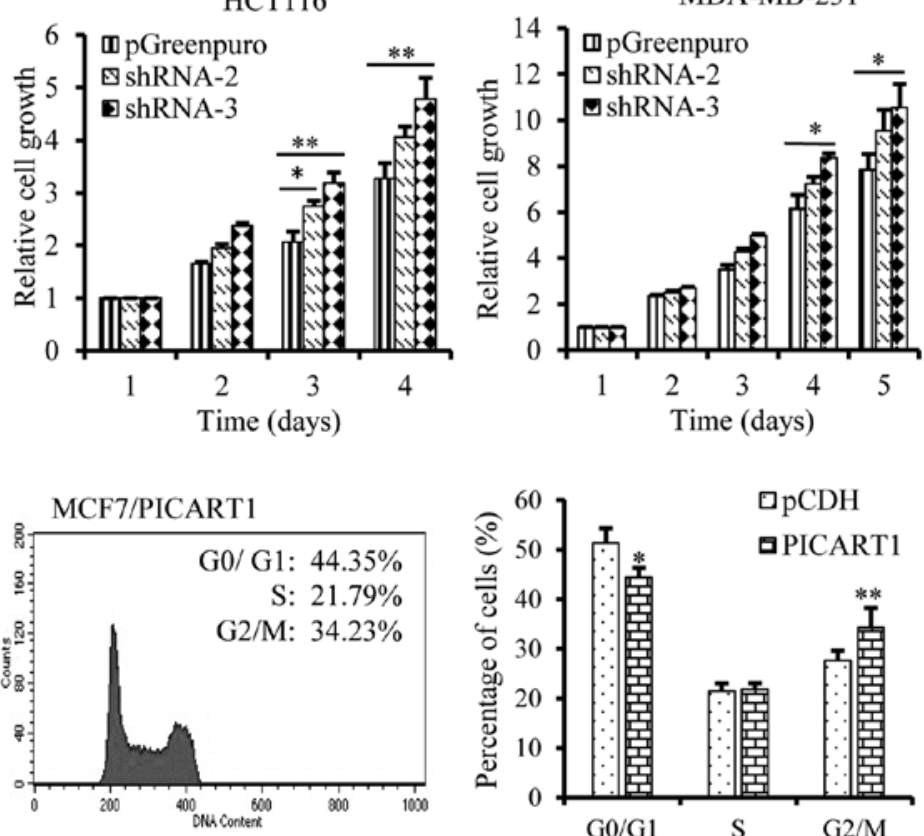

Figure 4. Inhibition of cell growth and proliferation by PICART1. (A) Ectopic expression or shRNA-mediated silencing of PICART1 in MCF7 and HCT116 cells. Cells were infected with lentivirus pCDH (vector control), PICART1, pGreenpuro (vector control), shRNA-2, shRNA-3 for $72 \mathrm{~h}$ and total RNAs were extracted using TRIzol reagent. PICART1 RNA levels were measured by quantitative real-time RT-PCR with GAPDH mRNA as an internal control. ${ }^{* *} \mathrm{P}<0.01$ compared to vector control. (B) Inhibition of cell growth by PICART1 expression, measured by MTT assays in 96-well plates. (C) Stimulation of cell growth by PICART1 silencing, measured by MTT assays in 96-well plates. (D) Cell cycle arrest. PICART1 expression cells were seeded at $1 \times 10^{6} \mathrm{cells} / 6-\mathrm{cm}$ dish and collected after $24 \mathrm{~h}$ to perform flow cytometry. Data indicate mean $\pm \mathrm{SD}$ from three independent experiments. ${ }^{*} \mathrm{P}<0.05$ and ${ }^{* * *} \mathrm{P}<0.01$ compared to controls.

eradicated its response to p53 (Fig. 3F). These data suggested that 553 upregulates the PICART1 expression through the p53 responsive element 1 in its promoter.

PICART1 inhibits cell proliferation, migration, and invasion. As a target of p53 tumor suppressor, we further estimated the biological function of PICART1 in cancer cells, using the ectopic expression and silencing cell models. Full length PICART1 cDNA was cloned for ectopic expression, and 3 PICART1-specific shRNA constructs were made for silencing. Fig. 4A shows the targeted ectopic expression (left) and silencing (right) of PICART1 in MCF7 and HCT116 cells. 
A
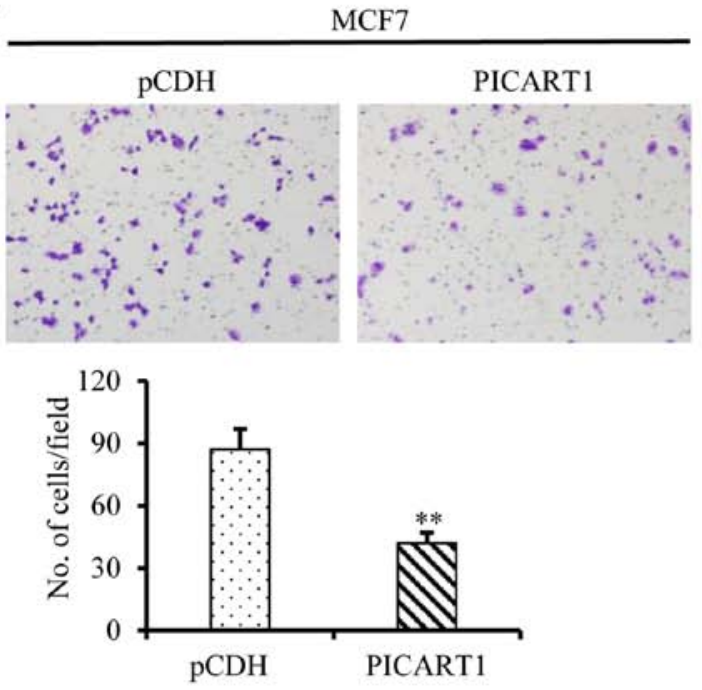
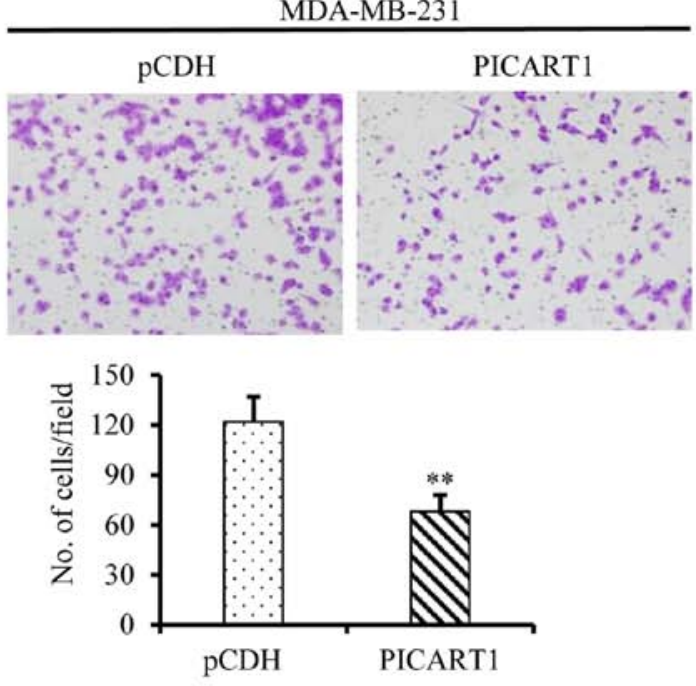

B

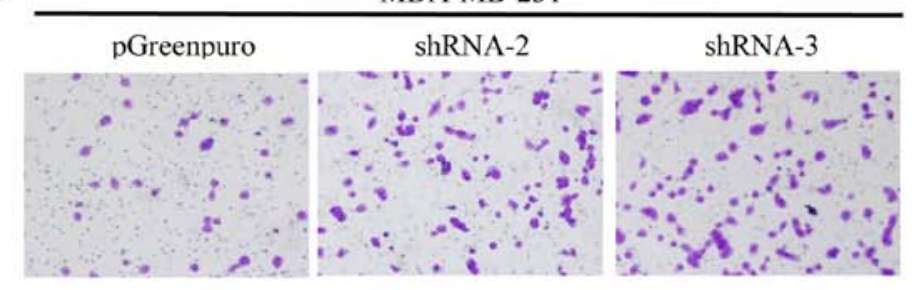

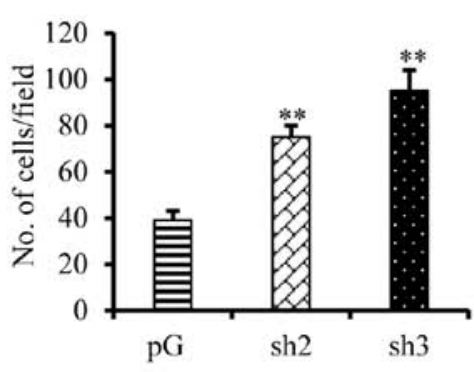

C
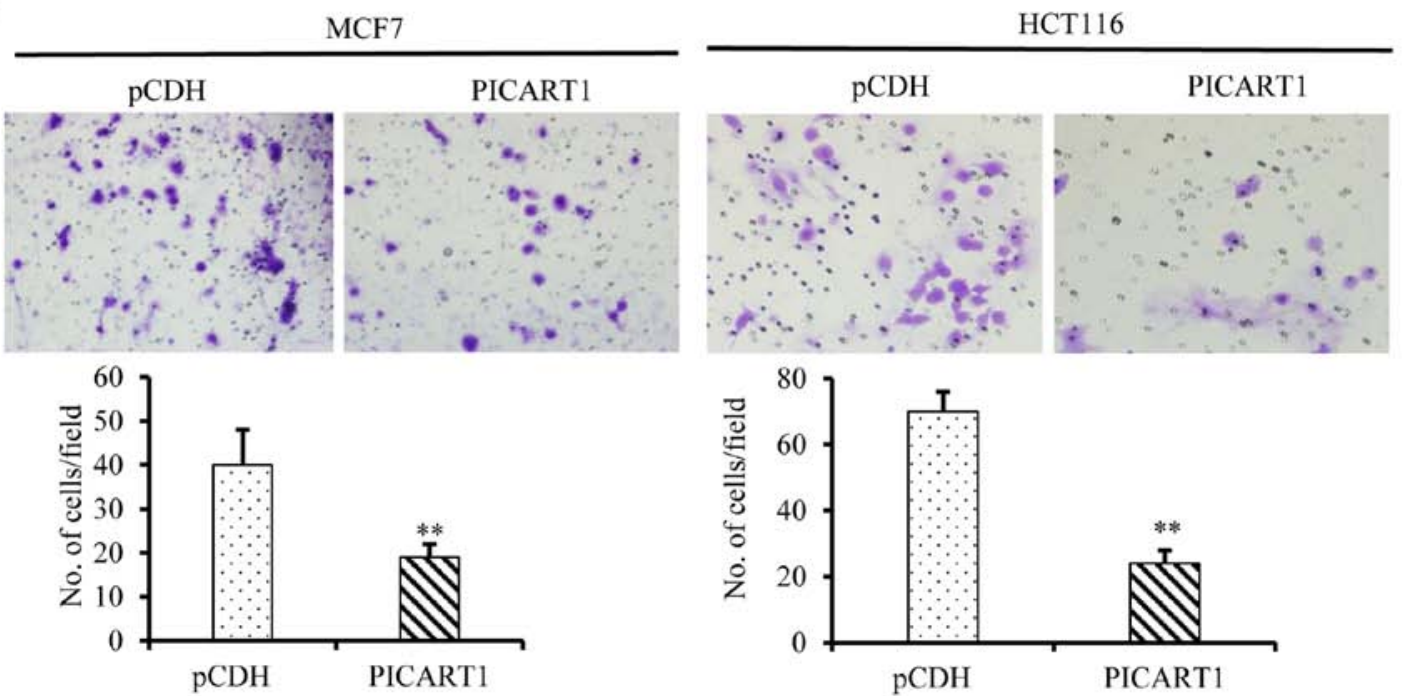

Figure 5. Inhibition of cell migration and invasion by PICART1. (A) Transwell migration of cells with PICART1 expression. MCF7 and MDA-MB-231 cells were split at $5 \times 10^{4}$ cells/insert in Transwell chambers. After incubation for $36 \mathrm{~h}$, upper cells in the chambers were removed and migrated cells in the bottom were stained with crystal violet for photographing and counting. (B) Transwell migration of cells with PICART1 silencing. MDA-MB-231 cells were split at $5 \times 10^{4}$ cells/insert and processed as described above. (C) Transwell invasion. MCF7 and HCT116 cells with PICART1 expression were split at 7x10 4 cells/insert in Transwell chambers coated with Matrigel. After $48 \mathrm{~h}$, cells were processed as described above. Data indicate mean \pm SD from three independent experiments. ${ }^{* *} \mathrm{P}<0.01$ compared to vector controls.

The data demonstrated that shRNA-2 and shRNA-3 knocked down PICART1 expression to $\sim 40-60 \%$ compared to the vector control. We estimated the cell growth and proliferation of these cell lines with targeted expression and silencing of PICART1, and the results showed that the ectopic expression of PICART1 notably inhibited the proliferation of MCF7 and
HCT116 cells as tested by MTT assays (Fig. 4B) and viable cell counting method (data not shown). In contrast, silencing of PICART1 by shRNAs led to an increase in cell growth and proliferation in the MCF7, HCT116 and MDA-MB-231 cells (Fig. 4C). Furthermore, FACScan analysis showed that PICART1 induced cell cycle arrest at the G2/M phase (Fig. 4D). 
A

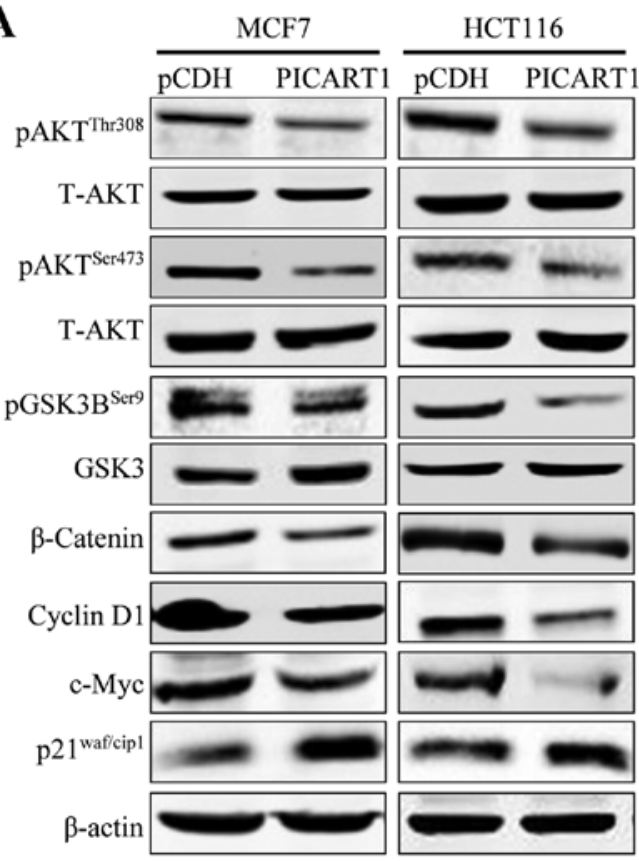

C
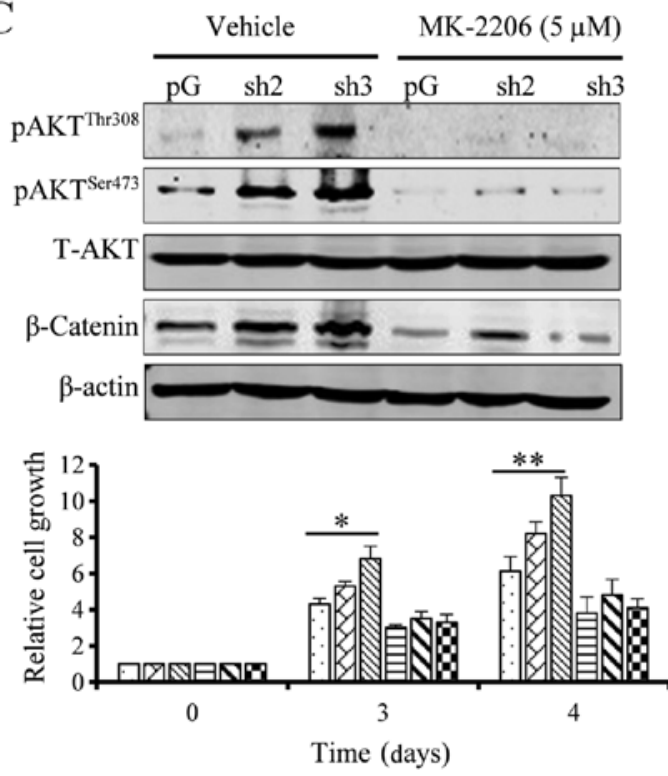

๑DMSO pGreenpuro שDMSO shRNA-2 DDMSO shRNA-3 EMK-2206 pGreenpuro DMK-2206 shRNA-2 MK-2206 shRNA-3
B

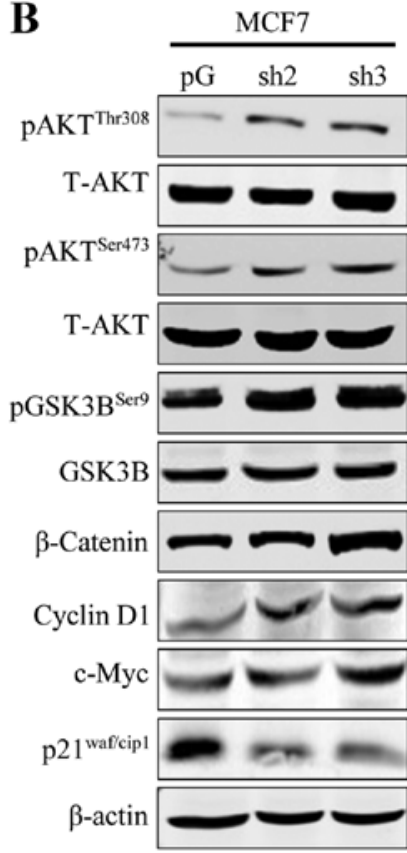

HCT116

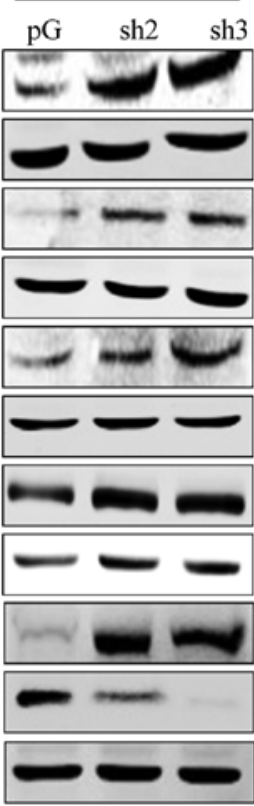

D


Figure 6. PICART1 regulates cell proliferation through the AKT/GSK3 $\beta / \beta$-catenin cascade. (A) Inhibition of the AKT/GSK3 $/ \beta$-catenin pathway effectors by PICART1 expression. (B) Activation of the AKT/GSK3 $\beta / \beta$-catenin pathway effectors by PICART1 silencing. (C) AKT inhibitor. MCF7 cells with PICART1 silencing were treated with 5.0 $\mu \mathrm{M}$ of MK-2206, an AKT inhibitor, for $24 \mathrm{~h}$. Protein expression and cell proliferation were estimated. "P<0.05 and ${ }^{* *} \mathrm{P}<0.01$ compared to the controls. (D) A hypothetic functional model of PICART1.

We further investigated the effects of PICART1 expression on migration and invasion of cancer cells. As shown in Fig. 5A, ectopic expression of PICART1 in MCF7 and MDA-MB-231 cells led to a notable decrease in the cell migration through micro-holes in the Transwells. In contrast, PICART1 silencing enhanced cell migration (Fig. 5B). Similar results were obtained in the invasion assays, and the ectopic expression of PICART1 suppressed the invasion of MCF7 and HCT116 cells (Fig. 5C). Altogether, these data suggest that PICART1 inhibits the proliferation, migration, and invasion of breast and colon cancer cells.
PICART1 regulates cell proliferation through the

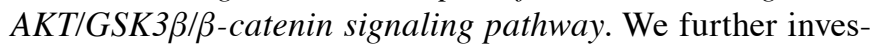
tigated the underlying mechanisms through which PICART1 functions. To address this question, we explored the effects of PICART1 expression on main oncogenic signaling pathways, such as AKT and ERK signaling. PICART1 did not have notable effects on ERK signaling (data not shown). However, as shown in Fig. 6A, ectopic expression of PICART1 led to a decrease in pAKT (Thr308 and Ser473), suggesting that PICART1 may function through the AKT signaling cascade. 
We then explored the downstream targets/effectors of AKT. Our results showed that pGSK $3 \beta$ (Ser9) and $\beta$-catenin expression was decreased by PICART1. $\beta$-catenin functions as a key transcription factor after translocation into the nucleus (22). As a result, the expression of cyclin D1 and c-Myc was decreased by PICART1 (Fig. 6A). c-Myc is a suppressor of p21 $1^{\text {Waf } 1 / \text { cip1 }}$ expression (23). Therefore, in the tested cells, we observed an increase in $\mathrm{p} 21^{\text {Waf } 1 / \mathrm{cipl}}$ expression due to downregulation of c-Myc by PICART1 (Fig. 6A). In contrast, silencing of PICART1 led to an increase in pAKT (Thr308 and Ser473), pGSK3B (Ser9), $\beta$-catenin, cyclin D1 and c-Myc expression but a decrease in $\mathrm{p} 21^{\text {Waf1/cip1 }}$ expression (Fig. 6B). To further confirm that PICART1 regulates cell growth and proliferation through the AKT $/ \beta$-catenin signaling pathway, we treated PICART1-silenced cells (where AKT signaling was activated) with 5.0 $\mu \mathrm{M}$ MK-2206, an AKT1/2 inhibitor. Our result showed that exposure to the AKT inhibitor abolished the stimulation of PICART1 silencing on cell proliferation (Fig. 6C). Taken together, our data suggest that PICART1 inhibits proliferation of MCF7 and HCT116 cells through control of the AKT/ GSK3 $\beta / \beta$-catenin pathway (Fig. 6D).

\section{Discussion}

Long non-coding RNAs (lncRNAs) are RNA transcripts in the genome which function as oncogenes or tumor suppressors, playing a critical role in cancer progression and development (24). This study characterized a new IncRNA named PICART1. PICART1 is p53-inducible and functions as a tumor suppressor via regulating the AKT/GSK $3 \beta / \beta$-catenin signaling pathway. This study also characterized a p53-response element in the promoter of the PICART1 gene.

p53 is a critical transcription factor that regulates expression of a wide range of genes, including protein-coding and non-coding genes. This makes p53 an important protein in multiple cellular processes, such as DNA repair and genome stability, cell cycle control, apoptosis, and senescence (25). As a transcription factor, p53 functions as a tetramer, binding to a sequence-specific response element in the promoter of target genes and controlling gene expression (26). This study revealed PICART1 as a new lncRNA target of p53, which is supported by several lines of evidence. The most direct evidence lies in the effects of targeted expression or silencing of p53 on the expression of endogenous PICART1 and on its promoter activity, and in the characterization of an active p53 response element in the PICART1 promoter. Targeted mutations of this element decreased the promoter activity at baseline and response to $\mathrm{p} 53$ expression or silencing. In addition, RITA is considered a 533 activator, restoring the function of p53 from its negative regulator HDM2 (MDM2 in mice); doxorubicin induces DNA damage and thus activates p53. Our results showed that both RITA and doxorubicin that activate 553 through different mechanisms triggered PICART1 expression, providing an additional line of evidence that p53 regulates PICART1 expression. However, p53 may not be the sole signaling pathway that regulates PICART1 expression. It is noted that in the tested cells, PICART1 expression was not stringently correlated with the p53 status. The PICART1 level was high in the non-transformed MCF10A cells that harbors a wild-type p53, but decreased in MCF7, HCT116, and HCT8 cells that also have a wild-type p53. It would be interested to further characterize the other factors that may affect PICART1 expression.

Our data showed that PICART1 expression was higher in response to RITA exposure than to ectopic p53 expression. This may be ascribed to the nature of different treatments. Unlike drug treatment, the efficiency of p53 transfection, i.e., the percentage of the cells transfected, rarely reaches $100 \%$. Thus, PICART1 expression was affected by p53 delivery only in a portion of cells. More importantly, p53 is a well-known cell apoptotic tumor suppressor (27). Gene transfection of p53 often leads to high expression and resultant cell death and RNA degradation, thus resulting in lower PICART1 induction observed in p53 delivery than in RITA exposure. In fact, PICART1 expression was downregulated much more efficiently in the p53-silenced cells due to the increased survival of these cells.

Promoter motif analysis recognized 3 putative 553 response elements in the PICART1 promoter, but only one was functional. The luciferase reporter activity assays showed that the full length of the promoter fragment $(-3000 \mathrm{bp})$ that contains all three elements presented a dose-dependent response to RITA treatment, while the promoter fragment -1592 bp that harbors the elements 2 and 3 was not responsive to RITA. This excluded the possibility that the elements 2 and 3 are functional p53 binding motifs. Therefore, our targeted mutation analyses were focused on element 1 located at -1808 to $-1783 \mathrm{bp}$, and our study results confirmed its activity responding to $\mathrm{p} 53$, thus strengthening the conclusion of p53 regulation on the PICART1 expression.

Cancer cells are characterized by unlimited growth and proliferation and increased migration and invasion, leading to development of tumors (28). p53-induced expression, coupled together with the decreased expression in cancer cells and tissues, suggests that PICART1 may function as a tumor suppressor. To test this hypothesis, we investigated the effects of targeted expression or silencing of PICART1 on proliferation, migration, and invasion of breast and colon cancer cells. Our result showed that ectopic expression of PICART1 suppressed cell proliferation and induced cell cycle arrest in G2/M phase while silencing of PICART1 enhanced cell proliferation. In addition, PICART1 expression markedly inhibited cell migration and invasion while silencing of PICART1 promoted cell migration and invasion. These results, along with the downregulation in breast and colon cancer, suggest that PICART1 acts as a tumor suppressor.

IncRNAs function as tumor suppressors through modulating cellular signaling networks (29). PI3K/AKT and $\mathrm{Wnt} / \beta$-catenin are two master oncogenic signals regulating cell proliferation, survival, migration, and invasion $(30,31)$. AKT is a serine-threonine kinase activated by phosphorylation at Thr308 and then Ser473 (32). In the canonical Wnt pathway, Wnt protein binds to Frizzled receptors, suppressing the activity of glycogen synthase kinase-3 $\beta$ (GSK3 $\beta$ ). Without Wnt signaling, $\beta$-catenin associates with Axin, adenomatosis polyposis (APC), protein phosphatase 2A (PP2A), glycogen synthase kinase $3 \beta$ (GSK3 $\beta$ ), and casein kinase $1 \alpha(\mathrm{CK} 1 \alpha)$, forming a destruction complex, degrading $\beta$-catenin by targeting for ubiquitination (33-35). An activation of Wnt signaling drives the destruction complex to translocation and 
disruption, allowing $\beta$-catenin accumulation and translocation into the nucleus. Once in the nucleus, $\beta$-catenin associates with Tcf/Lef transcription factors and drives expression of target genes, such as cyclin D1 and c-Myc, promoting cell proliferation and migration (22,36-38). AKT cross-talks with Wnt/ $\beta$-catenin signaling through phosphorylation at Ser9 and inactivation of GSK $3 \beta$ leading to increase of $\beta$-catenin level (39).

In this study, we found that PICART1 suppressed AKT activity with decreased phosphorylation levels of Thr308 and Ser473, which in turn lowered the pGSK3 $\beta$ (Ser9) and $\beta$-catenin levels, suppressing cyclin D1 and c-Myc expression. The latter is a repressive transcription factor of $\mathrm{p} 21^{\text {Waf } 1 / \mathrm{cip} 1}$ by sequestering SP1 (23). Thus we observed an increase in p21 $1^{\text {Waf } 1 / \text { cip } 1}$ expression by PICART1. It is currently unknown how PICART1 suppresses phosphorylation activation of AKT. Considering the multiple functional possibilities of IncRNAs, PICART1 may function as an adaptor to couple AKT with phosphatases, leading to dephosphorylation. PICART1 may also bind to AKT and block the access of AKT kinases for phosphorylation. Further study is warranted. It is also noteworthy that $\mathrm{p} 21^{\text {Waf1/cipl }}$ regulates both $\mathrm{G} 1 / \mathrm{S}$ and $\mathrm{G} 2 / \mathrm{M}$ transition $(40,41)$. In this study, targeted PICART1 expression induced cell cycle arrest at G2/M phase, but not at G1. It is well known that cell cycle regulation is a complicated event with involvement of multiple proteins, which may lead to differential phenotypes (42).

In summary, this study characterized a new lncRNA, named PICART1. PICART1 was upregulated by p53 through a sequence-specific response element in the promoter. PICART1 was downregulated in breast and colon cancer cells and tissues and functioned as a tumor suppressor, inhibiting cell proliferation, migration, and invasion through modulation of the AKT/ GSK3 $\beta / \beta$-catenin signaling cascade.

\section{Acknowledgements}

This research was supported in part by the National Natural Science Foundation of China (81272918 and 81472465 to D.C.).

\section{References}

1. Chung SW, Chen YH, Yet SF, Layne MD and Perrella MA: Endotoxin-induced down-regulation of Elk-3 facilitates heme oxygenase-1 induction in macrophages. J Immunol 176: 2414-2420, 2006.

2. Da Sacco L, Baldassarre A and Masotti A: Bioinformatics tools and novel challenges in long non-coding RNAs (lncRNAs) functional analysis. Int J Mol Sci 13: 97-114, 2012.

3. Hanahan D and Weinberg RA: The hallmarks of cancer. Cell 100: 57-70, 2000.

4. Schroeder JA, Adriance MC, Thompson MC, Camenisch TD and Gendler SJ: MUC1 alters beta-catenin-dependent tumor formation and promotes cellular invasion. Oncogene 22 : 1324-1332, 2003.

5. Zhao Y, Jian W, Gao W, Zheng YX, Wang YK, Zhou ZQ, Zhang $\mathrm{H}$ and Wang CJ: RNAi silencing of c-Myc inhibits cell migration, invasion, and proliferation in HepG2 human hepatocellular carcinoma cell line: c-Myc silencing in hepatocellular carcinoma cell. Cancer Cell Int 13: 23, 2013.

6. Sahu A, Singhal U and Chinnaiyan AM: Long noncoding RNAs in cancer: From function to translation. Trends Cancer 1: 93-109, 2015.

7. Bhan A and Mandal SS: IncRNA HOTAIR: A master regulator of chromatin dynamics and cancer. Biochim Biophys Acta 1856: $151-164,2015$.
8. Yuan JH, Yang F, Wang F, Ma JZ, Guo YJ, Tao QF, Liu F, Pan W, Wang TT, Zhou CC, et al: A long noncoding RNA activated by TGF- $\beta$ promotes the invasion-metastasis cascade in hepatocellular carcinoma. Cancer Cell 25: 666-681, 2014.

9. Xing Z, Lin A, Li C, Liang K, Wang S, Liu Y, Park PK, Qin L, Wei Y, Hawke DH, et al: lncRNA directs cooperative epigenetic regulation downstream of chemokine signals. Cell 159: $1110-1125,2014$

10. Gutschner T, Hämmerle M, Eissmann M, Hsu J, Kim Y, Hung G, Revenko A, Arun G, Stentrup M, Gross M, et al: The noncoding RNA MALAT1 is a critical regulator of the metastasis phenotype of lung cancer cells. Cancer Res 73: 1180-1189, 2013.

11. Zhao Y, Yang Y, Trovik J, Sun K, Zhou L, Jiang P, Lau TS, Hoivik EA, Salvesen HB, Sun H, et al: A novel wnt regulatory axis in endometrioid endometrial cancer. Cancer Res 74: 5103-5117, 2014.

12. Shen Y, Ma J, Yan R, Ling H, Li X, Yang W, Gao J, Huang C, $\mathrm{Bu} \mathrm{Y,} \mathrm{Cao} \mathrm{Y,} \mathrm{et} \mathrm{al:} \mathrm{Impaired} \mathrm{self-renewal} \mathrm{and} \mathrm{increased} \mathrm{colitis}$ and dysplastic lesions in colonic mucosa of AKR1B8-deficient mice. Clin Cancer Res 21: 1466-1476, 2015.

13. Cao D, Fan ST and Chung SS: Identification and characterization of a novel human aldose reductase-like gene. J Biol Chem 273: 11429-11435, 1998

14. Liu Z, Yan R, Al-Salman A, Shen Y, Bu Y, Ma J, Luo DX, Huang C, Jiang Y, Wilber A, et al: Epidermal growth factor induces tumour marker AKR1B10 expression through activator protein-1 signalling in hepatocellular carcinoma cells. Biochem J 442: 273-282, 2012.

15. Bu Y, Li X, He Y, Huang C, Shen Y, Cao Y, Huang D, Cai C, Wang Y, Wang Z, et al: A phosphomimetic mutant of RelA/p65 at Ser536 induces apoptosis and senescence: An implication for tumor-suppressive role of Ser536 phosphorylation. Int J Cancer 138: 1186-1198, 2016.

16. Ma J, Yan R, Zu X, Cheng JM, Rao K, Liao DF and Cao D: Aldo-keto reductase family $1 \mathrm{~B} 10$ affects fatty acid synthesis by regulating the stability of acetyl-CoA carboxylase-alpha in breast cancer cells. J Biol Chem 283: 3418-3423, 2008.

17. Liu Z, Zhong L, Krishack PA, Robbins S, Cao JX, Zhao Y, Chung S and Cao D: Structure and promoter characterization of aldo-keto reductase family 1 B10 gene. Gene 437: 39-44, 2009.

18. Huang C, Verhulst S, Shen Y, Bu Y, Cao Y, He Y, Wang Y, Huang D, Cai C, Rao K, et al: AKR1B10 promotes breast cancer metastasis through integrin $\alpha 5 / \delta$-catenin mediated $\mathrm{FAK} / \mathrm{Src} / \mathrm{Rac} 1$ signaling pathway. Oncotarget 7: 43779-43791, 2016.

19. Yan R, Zu X, Ma J, Liu Z, Adeyanju M and Cao D: Aldo-keto reductase family $1 \mathrm{~B} 10$ gene silencing results in growth inhibition of colorectal cancer cells: Implication for cancer intervention. Int J Cancer 121: 2301-2306, 2007.

20. Harris SL and Levine AJ: The p53 pathway: Positive and negative feedback loops. Oncogene 24: 2899-2908, 2005.

21. Issaeva N, Bozko P, Enge M, Protopopova M, Verhoef LG, Masucci M, Pramanik A and Selivanova G: Small molecule RITA binds to p53, blocks p53-HDM-2 interaction and activates p53 function in tumors. Nat Med 10: 1321-1328, 2004.

22. Tetsu $\mathrm{O}$ and McCormick F: Beta-catenin regulates expression of cyclin D1 in colon carcinoma cells. Nature 398: 422-426, 1999.

23. Gartel AL, Ye X, Goufman E, Shianov P, Hay N, Najmabadi F and Tyner AL: Myc represses the p21(WAF1/CIP1) promoter and interacts with Sp1/Sp3. Proc Natl Acad Sci USA 98: 4510-4515, 2001.

24. Gibb EA, Brown CJ and Lam WL: The functional role of long non-coding RNA in human carcinomas. Mol Cancer 10: 38, 2011.

25. Harris CC: Structure and function of the p53 tumor suppressor gene: Clues for rational cancer therapeutic strategies. J Natl Cancer Inst 88: 1442-1455, 1996.

26. Riley T, Sontag E, Chen P and Levine A: Transcriptional control of human p53-regulated genes. Nat Rev Mol Cell Biol 9: 402-412, 2008.

27. Cao Z, Ma J, Chen X, Zhou B, Cai C, Huang D, Zhang X and Cao D: Uridine homeostatic disorder leads to DNA damage and tumorigenesis. Cancer Lett 372: 219-225, 2016.

28. Schmitz AA, Govek EE, Böttner B and Van Aelst L: Rho GTPases: Signaling, migration, and invasion. Exp Cell Res 261: $1-12,2000$.

29. Prensner JR and Chinnaiyan AM: The emergence of lncRNAs in cancer biology. Cancer Discov 1: 391-407, 2011.

30. Kim YG, Kim MJ, Lim JS, Lee MS, Kim JS and Yoo YD: ICAM-3-induced cancer cell proliferation through the PI3K/Akt pathway. Cancer Lett 239: 103-110, 2006. 
31. Li X, Xu Y, Chen Y, Chen S, Jia X, Sun T, Liu Y,Li X, Xiang R and Li N: SOX2 promotes tumor metastasis by stimulating epithelialto-mesenchymal transition via regulation of $\mathrm{WNT} / \beta$-catenin signal network. Cancer Lett 336: 379-389, 2013.

32. Valenta T, Hausmann $G$ and Basler K: The many faces and functions of $\beta$-catenin. EMBO J 31: 2714-2736, 2012.

33. Nakamura T, Hamada F, Ishidate T, Anai K, Kawahara K, Toyoshima $\mathrm{K}$ and Akiyama T: Axin, an inhibitor of the Wnt signalling pathway, interacts with beta-catenin, GSK-3beta and APC and reduces the beta-catenin level. Genes Cells 3: 395-403, 1998.

34. Luo J: Glycogen synthase kinase 3beta (GSK3beta) in tumorigenesis and cancer chemotherapy. Cancer Lett 273: 194-200, 2009.

35. Minde DP, Anvarian Z, Rüdiger SG and Maurice MM: Messing up disorder: How do missense mutations in the tumor suppressor protein APC lead to cancer? Mol Cancer 10: 101, 2011.

36. Kolligs FT, Bommer G and Göke B: Wnt/beta-catenin/tcf signaling: A critical pathway in gastrointestinal tumorigenesis. Digestion 66: 131-144, 2002.

37. MacDonald BT, Tamai $\mathrm{K}$ and He X: Wnt/beta-catenin signaling: Components, mechanisms, and diseases. Dev Cell 17: 9-26, 2009.
38. Li YJ, Wei ZM, Meng YX and Ji XR: Beta-catenin up-regulates the expression of cyclinD1, c-myc and MMP-7 in human pancreatic cancer: Relationships with carcinogenesis and metastasis. World J Gastroenterol 11: 2117-2123, 2005.

39. Fang D, Hawke D, Zheng Y, Xia Y, Meisenhelder J, Nika H, Mills GB, Kobayashi R, Hunter T and Lu Z: Phosphorylation of beta-catenin by AKT promotes beta-catenin transcriptional activity. J Biol Chem 282: 11221-11229, 2007.

40. Niculescu AB III, Chen X, Smeets M, Hengst L, Prives C and Reed SI: Effects of p21(Cip1/Waf1) at both the G1/S and the $\mathrm{G} 2 / \mathrm{M}$ cell cycle transitions: $\mathrm{pRb}$ is a critical determinant in blocking DNA replication and in preventing endoreduplication. Mol Cell Biol 18: 629-643, 1998.

41. Bunz F, Dutriaux A, Lengauer C, Waldman T, Zhou S, Brown JP, Sedivy JM, Kinzler KW and Vogelstein B: Requirement for p53 and p21 to sustain G2 arrest after DNA damage. Science 282: 1497-1501, 1998.

42. Chan TA, Hwang PM, Hermeking H, Kinzler KW and Vogelstein B: Cooperative effects of genes controlling the G(2)/M checkpoint. Genes Dev 14: 1584-1588, 2000. 